RU Исследовательская компетенция студентов-лингвистов на основе практико-ориентированного подхода: характеристики и аспекты формирования

Чжан Сюань, Щеглова И. В.

Аннотация. Цель исследования заключается в представлении сущности феномена «исследовательская компетенция лингвистов». В статье рассматриваются характеристики и аспекты формирования исследовательской компетенции студентов-лингвистов в контексте практико-ориентированного подхода. Научная новизна заключается в выделении специфических черт исследовательской компетенции лингвистов, установленных на основе анализа данных опроса студентов-иностранцев, изучающих английский язык как язык международного общения и русский язык как иностранный; в иллюстрации аспектов развития обозначенной компетенции исходя из ее компонентов: мотивационного, информационного, когнитивного (коммуникативного), операционно-деятельностного, рефлексивного, креативного, личностного. В результате исследования устанавливается, что фокусная группа детерминирует характеристики и аспекты формирования исследовательской компетенции.

\title{
EN Forming Linguistic Students' Research Competence on the Basis of a Practice-Oriented Approach
}

\author{
Zhang Xuan, Shcheglova I. V.
}

\begin{abstract}
The paper aims to reveal essence of the notion "linguistic research competence". The article considers the characteristics of research competence, examines the process of research competence formation among linguistic students on the basis of a practice-oriented approach. Scientific originality of the study lies in the fact that relying on a survey conducted among foreign students studying English as a language of international communication and Russian as a foreign language the authors identify specific features of linguistic research competence, reveal the aspects of research competence formation taking into account its components: motivational, informational, cognitive (communicative), activity-based, reflexive, creative, personal. As a result, it is shown that focus group method allows representing research competence characteristics and provides deeper understanding of research competence formation.
\end{abstract}

\section{Введение}

Актуальность исследования определяется следующими факторами: 1) компетентностный подход в высшем образовании является его ключевой характеристикой, так как ориентирует систему образования на обеспечение качества подготовки в соответствии с потребностями общества, что согласуется не только с потребностью личности интегрироваться в общественную деятельность, но и потребностью самого общества использовать потенциал личности, вместе с тем многие теоретические вопросы данной области относятся к числу дискуссионных, в частности характеристики компетенций, подходы к их формированию; 2) научная деятельность играет важную роль как в жизни отдельного индивида, так и общества в целом; 3) в условиях многоязычия формирование исследовательской компетенции требует комплексного анализа. В этой связи обращение к изучению исследовательской компетенции студентов-лингвистов на основе практико-ориентированного подхода является оправданным и своевременным.

Данная статья преследует следующие задачи:

- дать характеристику понятию исследовательская компетенция;

- выделить релевантные особенности исследовательской компетенции студентов-лингвистов;

- обозначить аспекты развития исследовательской компетенции студентов-лингвистов на основе практикоориентированного подхода. 
В ходе исследования использован комплекс общенаучных методов и приемов (описательный, индуктивный, дедуктивный, методы дефиниционного и контекстуального анализа), элементы количественного анализа.

Работа базируется на следующих положениях, доказанных в педагогической литературе.

Исследовательская компетенция представляет собой совокупность способностей личности, позволяющих осуществлять деятельность, которая направлена на приобретение научных знаний (Арцев, 2005; Ефричева, Мельник, Михайлюкова, 2021; Леонтович, 2004).

Овладение обучающимися исследовательской компетенцией предполагает ряд умений (Трофимов, Трофимова, Минаков и др., 2018).

Исследовательская компетенция является неотъемлемой характеристикой профессионала (Шашкина, Багачук, 2006).

Теоретическая значимость исследования усматривается в том, что оно вносит вклад в развитие компетентностного подхода в образовании, уточняя характеристики исследовательской компетенции студентовлингвистов.

Практическую ценность работы видим в том, что ее результаты могут найти применение в курсах методики преподавания и стилистики иностранных языков, а именно в разработке системы упражнений для обеспечения всестороннего развития исследовательской компетенции.

\section{Характеристика понятия «исследовательская компетенция»}

Под компетенцией, вслед за А. В. Хуторским (2003), понимаем «круг вопросов, в котором человек хорошо осведомлен, обладает познанием и опытом; это совокупность взаимосвязанных качеств личности (знаний, умений, навыков, способов деятельности), задаваемых по отношению к определенному кругу предметов и процессов и необходимых для качественной продуктивной деятельности» (с. 109).

Что касается определения понятия исследовательская компетенция, то считаем целесообразным подчеркнуть, что нам не встретилось толкование данного термина в словарях и энциклопедиях. Вместе с тем анализ рассматриваемого понятия получил отражение в работах исследователей (Арцев, 2005; Ефричева, Мельник, Михайлюкова, 2021; Зданович, 2012; Леонтович, 2004; Мишурина, 2016; Фёдорова, 2011; Хуторской, 2011).

По определению О. Ю. Ефричевой, И. В. Мельник, В. С. Михайлюковой (2021), «исследовательская компетенция - это совокупность знаний, способностей, навыков и опыта в проведении исследования, получении определенного нового знания, нового интеллектуального продукта, создания нового проекта, нового решения проблемы; качества и умения, которые человек должен проявлять в проведении эффективного исследования любого вопроса».

Конкретизирует анализируемое понятие А. В. Леонтович (2004): «...деятельность обучающихся, основанная на творческом подходе к решению задач, с неизвестным заранее решением. Выделяется ряд этапов, характерных для исследований в научной области: определение проблемы, анализ теории, выдвижение гипотез, определение методик и умение практического их применения, способность делать самостоятельные выводы и презентовать работу» (с. 89). Таким образом, автор подчеркивает следующие моменты: творческий подход к решению задач, неизвестное заранее решение; наряду с этим выделяет этапы научного исследования. Похожим является взгляд на дефиницию анализируемого словосочетания М. Н. Арцева (2005): «...особый род деятельности, который направлен на приобретение новых точных научных знаний, с заранее неизвестным концом решения проблемной ситуации» (с. 29).

Дополнить представленные определения следует констатацией того, что на современном этапе развития общества значение научного знания неоспоримо. В связи с этим исследовательская компетенция рассматривается как неотъемлемая характеристика профессионала. М. Б. Шашкина и А. В. Багачук (2006) подчеркивают, что «исследовательская компетенция имеет интегративную характеристику личности, которая предполагает владение методологическими знаниями, технологией исследовательской деятельности, признание и готовность к их использованию в профессиональной деятельности, отличающуюся устойчивой мотивацией» (с. 113).

Таким образом, под исследовательской компетенцией понимаем совокупность взаимосвязанных качеств личности, задаваемых по отношению к исследовательской деятельности и необходимых для получения результатов, отличающихся теоретической значимостью и практической ценностью.

\section{Релевантные особенности исследовательской компетенции студентов-лингвистов}

В. В. Трофимов (Трофимов, Трофимова, Минаков и др., 2018) указывает, что овладение обучающимися исследовательской компетенцией предполагает следующие умения:

- правильно определять задачу исследования;

- умение описывать и делать выводы;

- формулировать рекомендации;

- находить нестандартные решения;

- проявлять инициативу;

- быть готовым к самостоятельному поиску информации;

- быть достаточно компетентным в методах независимых исследований; 
- уметь интерпретировать результаты на высоком уровне;

- быть готовым к проектной и исследовательской деятельности (с. 62).

Представляется, что исследовательская компетенция, несмотря на универсальность, применительно к студентам-лингвистам имеет ряд специфических черт. Нам удалось выделить некоторые из них:

1) приоритет владения языком над умением наглядно представлять материал (схемы, таблицы, диаграммы);

2) роль творческого подхода выше, чем при исследованиях в других областях. Данный подход позволяет найти и заполнить содержательные лакуны в той или иной области;

3) вероятность возникновения трудностей в процессе обработки полученных данных исследования.

Обозначенные положения выделены на основе результата опроса студентов-иностранцев, изучающих английский язык как язык международного общения и русский язык как иностранный. Указанная фокусная группа представляет интерес, так как средством формирования компетенции служит несколько языков. Поясним: студенты принимают активное участие в подготовке статей WoS и Scopus, в то же время пишут магистерские диссертации на русском языке. В рамках анкетирования предлагалось выполнить следующее открытое задание: «Отметьте ключевые характеристики исследовательской компетенции студентов-лингвистов; укажите трудности, которые могут возникать в процессе ее формирования».

Подчеркнем, что применительно к предмету нашего исследования среди принципов организации исследовательской деятельности обучающихся следует обозначить в первую очередь принцип становления межъязыковых связей в ситуации учебного билингвизма. Вместе с тем значимыми являются принципы организации исследовательской деятельности, предложенные В. В. Трофимовым (2018, с. 66-67): принцип мотивации обучающихся к исследовательской деятельности; принцип непрерывности исследовательской деятельности; принцип интеграции учебной и исследовательской деятельности; принцип интеграции проектной и исследовательской деятельности; принцип интеграции научной и исследовательской деятельности; принцип межпредметности; принцип системности; принцип преемственности; принцип самоорганизации исследовательской деятельности; принцип наставничества (совместная деятельность обучающегося и руководителя-исследователя).

В рамках теории целесообразно обозначить и аргументировать подход, выбранный для развития исследовательской компетенции студентов-лингвистов. Считаем логичным обращение к практико-ориентированному подходу, исходя из следующих научных положений, доказанных в педагогической литературе:

- «...практико-ориентированный [подход] является одним из эффективных подходов к формированию полилингвальной личности будущего педагога, что предполагает проведение обучения иностранному языку на основе активной профессиональной деятельности обучающихся и их личной заинтересованности в приобретении знаний» (Бабушкина, Шукшина, 2020, с. 182);

- концепция OBE-CDIO (расшифровывается как «Образование-Результат») предназначена для усиления практической направленности и оптимизации системы проблемного и проектного обучения. Объединяет несколько подходов к практико-ориентированному обучению, в том числе практико-ориентированное образование, направленное на приобретение, кроме знаний, умений, навыков, опыта практической деятельности с целью достижения профессионально и социально значимых компетентностей (Будажапова, Ли, Бушуева, 2020, с. 94).

Таким образом, материал исследования позволил установить релевантные особенности исследовательской компетенции студентов-лингвистов: приоритет владения языком над умением наглядно представлять материал; высокая степень креативности; вероятность возникновения проблем в процессе обработки данных исследования.

\section{Аспекты развития исследовательской компетенции студентов-лингвистов на основе практико-ориентированного подхода}

Процесс развития исследовательской компетенции представляет собой динамическую иерархию, состоящую из последовательно формируемых компонентов.

Согласно позиции В. В. Трофимова (Трофимов, Трофимова, Минаков и др., 2018), «исследовательская компетентность формируется у обучающегося через взаимосвязь ее основных компонентов: 1) мотивационного; 2) информационного; 3) когнитивного (коммуникативного); 4) операционно-деятельностного; 5) рефлексивного; 6) креативного; 7) личностного» (с. 66).

Представим направления работы по развитию исследовательской компетенции исходя из обозначенных компонентов:

1. Развитие мотивационной основы по выбору темы выпускной квалификационной работы. В данном контексте целесообразна работа по репрезентации актуальных направлений современной русистики: лингвокультурологии, теории дискурса, социолингвистики, методики преподавания языка и литературы. В частности, опыт показывает, в качестве материала исследования логично обращаться к периодическому изданию «Русистика» (РУДН). После знакомства с направлениями, а также тематикой исследований в выбранном направлении целесообразно предложить студентам сформулировать 2-3 темы в рамках каждого из них. Например, лингвокультурология: «Осмысление ценностных доминант межкультурного общения», теория дискурса: «Вербальный аспект взаимодействия в условиях дистанционного обучения» и т.д.

2. Развитие навыков поиска и обработки информации. Иностранные студенты с желанием работают с крупнейшим российским информационно-аналитическим порталом eLIBRARY.RU. Данный ресурс позволяет развивать навыки работы с ключевыми словами и аннотацией, осуществлять подборку статей. При этом 
полезны взаимообратные упражнения: с одной стороны, соотнести аннотацию и ключевые слова с научными работами, с другой стороны, выделить ключевые слова и написать аннотацию к статье.

3. Развитие умений анализировать и систематизировать материал. В данном ключе возможна следующая работа: студентам предлагается ряд определений понятия «компетенция», ставится задача разработать научный текст «Компетенция: определение, характеристики». В качестве пропедевтической работы логично рассмотреть варианты выполнения подобных заданий на другие темы (выделить достоинства и недостатки каждой из них). Кроме того, важно дать четкую установку студентам: представить критический анализ материала с обозначенной авторской позицией.

4. Развитие навыков по выбору методов, средств, форм организации исследовательской деятельности. Полагаем, акцентировать внимание целесообразно на развитии лабильности автора. Среди многообразия упражнений обозначим анализ анкет, которому предшествует разъяснение темы, цели эксперимента; презентация фокусной группы с последующим решением проблемной ситуации: Все ли искомые данные обнаружены? Как можно заполнить имеющиеся лакуны? Какие методы, средства, формы оптимальны в конкретном случае?

5. Развитие навыков по распознаванию, оцениванию и анализу исследовательских явлений, не только собственных, но и окружающей среды. В данном аспекте полезно решение проблемных ситуаций следующего образца: Вы занимаетесь изучением проблемы формирования исследовательской компетенции студентовлингвистов на основе практико-ориентированного подхода. Ситуация: прошла защита диссертации по данной тематике. Ваши действия?

6. Развитие умений поиска нестандартного решения на основе анализа объекта исследования в рамках междисциплинарного подхода. На занятиях студентам предлагается определить возможные пути изучения того или иного объекта, определить науки, в рамках которых будет выполняться исследование.

7. Развитие навыков самоорганизации, самообучения, саморегуляции и саморазвития. Ряд умений также можно формировать в процессе работы с порталом eLIBRARY.RU, который снабжен рядом функций: например, добавить публикацию в подборку. Это позволит студентам составить авторскую библиотеку интересующих изданий, работа с которыми будет способствовать их саморазвитию.

Итак, подчеркивая многокомпонентную структуру исследовательской компетенции студентов-лингвистов, определили аспекты ее совершенствования: развитие мотивационной основы по выбору темы выпускной квалификационной работы; развитие навыков поиска и обработки информации; развитие умений анализировать и систематизировать материал; развитие навыков по выбору методов, средств, форм организации исследовательской деятельности; развитие навыков по распознаванию, оцениванию и анализу исследовательских явлений, не только собственных, но и окружающей среды; развитие умений поиска нестандартного решения на основе анализа объекта исследования в рамках междисциплинарного подхода; развитие навыков самоорганизации, самообучения, саморегуляции и саморазвития.

\section{Заключение}

Материал исследования позволил прийти к выводу о том, что фокусная группа детерминирует характеристики и аспекты формирования исследовательской компетенции.

Согласно нашей точке зрения, исследовательская компетенция представляет собой совокупность взаимосвязанных качеств личности, задаваемых по отношению к исследовательской деятельности и необходимых для получения результатов, отличающихся теоретической значимостью и практической ценностью. Исследовательская компетенция студентов-лингвистов характеризуется рядом особенностей, среди которых целесообразно выделить следующие: приоритет владения языком над умением наглядно представлять материал; высокая степень креативности; вероятность возникновения проблем в процессе обработки данных исследования.

Исследовательская компетенция имеет сложную структуру. В связи с этим ее развитие логично осуществлять комплексно - исходя из компонентов (мотивационного, информационного, когнитивного, операционнодеятельностного, рефлексивного, креативного, личностного). При формировании исследовательской компетенции студентов-лингвистов целесообразно обращаться к практико-ориентированному подходу.

В перспективе на основе представленного материала планируем провести педагогический эксперимент и описать его результаты, полученные на основе сопоставления данных экспериментальной и контрольной групп.

\section{Источники | References}

1. Арцев М. Н. Учебно-исследовательская работа учащихся: методические рекомендации для учащихся и педагогов // Завуч. 2005. № 6.

2. Бабушкина Л. Е., Шукшина Т. И. Критерии эффективности формирования полилингвальной личности будущих педагогов на основе практико-ориентированного подхода // Kant. 2020. № 2 (35).

3. Будажапова Б. Б., Ли Т., Бушуева Е. О. Практико-ориентированный OBE-CDIO подход к обучению китайских студентов русскому языку // Вестник Воронежского государственного университета. Серия: Проблемы высшего образования. 2020. № 3.

4. Ефричева О. Ю., Мельник И. В., Михайлюкова В. С. Исследовательская компетенция: ее сущность и содержание. 2021. URL: https://apni.ru/article/2147-issledovatelskaya-kompetentsiya-ee-sushchnost 
5. Зданович О. В. О структуре и содержании исследовательской компетенции студентов - будущих учителей // Вестник Томского государственного педагогического университета. 2012. № 11 (126).

6. Леонтович А. В. Модель научной школы и практика организации исследовательской деятельности учащихся // Школьные технологии. 2004. № 5.

7. Мишурина О. А. Теоретико-методологические аспекты процесса формирования исследовательской компетенции студентов технического университета // Международный журнал прикладных и фундаментальных исследований. 2016. № 11 (5).

8. Трофимов В. В., Трофимова Л. А., Минаков В. Ф. и др. Система формирования исследовательских компетенций и технологических заделов в научной и образовательной деятельности. СПб.: Санкт-Петербургский экономический государственный университет, 2018.

9. Федорова И. А. Структура исследовательской компетенции бакалавров образования и педагогики: международный и отечественный аспекты. 2011. URL: https://evestnik-mgou.ru/ru/Articles/View/86

10. Хуторской А. В. Дидактическая эвристика. Теория и технология креативного обучения. М.: Изд-во МГУ, 2003.

11. Хуторской А. В. Исследовательские компетенции ученика и педагога в условиях научной школы человекосообразного образования // Вестник Института образования человека. 2011. № 1.

12. Шашкина М. Б., Багачук А. В. Формирование исследовательской деятельности студентов педагогического вуза в условиях реализации компетентностного подхода: монография. Красноярск: КГПУ им. В. П. Астафьева, 2006.

\section{Информация об авторах | Author information}

\section{RU Чжан Сюань}

Щеглова Инна Владимировна ${ }^{2}$, д. филол. н.

1,2 Санкт-Петербургский политехнический университет Петра Великого

EN Zhang Xuan ${ }^{1}$

Shcheglova Inna Vladimirovna ${ }^{2}$, Dr

${ }^{1,2}$ Peter the Great Saint Petersburg Polytechnic University

${ }^{1}$ fangxiatui@gmail.com, 2 isheglova@yahoo.com

\section{Информация о статье | About this article}

Дата поступления рукописи (received): 05.11.2021; опубликовано (published): 28.12.2021.

Ключевые слова (keywords): исследовательская компетенция; практико-ориентированный подход; иностранные студенты; студенты-лингвисты; research competence; practice-oriented approach; foreign students; linguistic students. 